\title{
Efeitos do ácido L-glutâmico e da vitamina K na composição bioquímica parcial de fêmures de frangos de corte ${ }^{1}$
}

\author{
George Henrique Kling de Moraes $^{2}$, Ana Claudia Peres Rodrigues ${ }^{3}$, Fernanda Álvares da \\ Silva $^{2}$, Horacio Santiago Rostagno ${ }^{3}$, Cibele Silva Minafra ${ }^{2}$, Solange Mara Bigonha ${ }^{2}$ \\ 1 Financiado pela FAPEMIG. \\ 2 Departamento de Bioquímica e Biologia Molecular, UFV, CEP: 36570-000, Viçosa, MG. \\ ${ }^{3}$ Departamento de Zootecnia, UFV, CEP: 36570-000, Viçosa, MG.
}

RESUMO - Objetivou-se estudar os efeitos da combinação de ácido L-glutâmico (L-Glu) e vitamina K na composição bioquímica de fêmures (proteínas colagenosas; não-colagenosas e totais) de frangos de corte. O experimento, que teve 14 dias de duração, foi conduzido em delineamento inteiramente casualizado, em fatorial $2 \times 4$, com dois níveis de ácido L-glutâmico (6,25 e 12,5\%) combinados com quatro níveis de vitamina $\mathrm{K}(0,02 ; 0,2 ; 2,0$ e $20,0 \mathrm{mg} / \mathrm{kg}$ de ração), cada combinação com quatro repetições de dez animais. Foram utilizados pintos machos, Avian Farm, de 1 dia, criados em baterias aquecidas e alimentados à vontade com dieta básica contendo L-aminoácidos essenciais, minerais e vitaminas (exceto vitamina K) suplementada com ácido L-glutâmico e vitamina K. Ao término do experimento, os animais foram sacrificados por deslocamento cervical e seus fêmures removidos, medidos, desengordurados e pesados. Não foi observada interação significativa entre ácido L-glutâmico e vitamina K para os parâmetros estudados. Os teores de proteínas não-colagenosas foram maiores e o de proteínas colagenosas, menores nos fêmures dos pintos alimentados com a ração com 6,25\% de ácido L-glutâmico. Os teores de proteínas totais, no entanto, não foram afetados pelos níveis de ácido L-glutâmico e de vitamina K. Os níveis de vitamina $\mathrm{K}$ tiveram efeito quadrático decrescente nos teores de proteínas não-colagenosas e efeito crescente na composição de proteínas colagenosas dos fêmures. A composição em proteínas colagenosas e não-colagenosas pode ser utilizada como indicador bioquímico de anormalidades de pernas causadas por baixo nível de nitrogênio não-específico.

Palavras-chave: glutamato, menadiona, osso, proteínas colagenosas, proteínas não-colagenosas

\section{Effects of dietary L-glutamic acid and $\mathrm{K}$ vitamin in the biochemical composition in femurs of broilers at 14 days of age}

\footnotetext{
ABSTRACT - This work aimed to study the effects of L-glutamic acid (L-Glu) and K vitamin on the biochemical composition (collagenous proteins, CP; non collagenous proteins, NCP; and total proteins, TP) in femurs of broilers. The experiment which lasted for 14 days, was carried out in a completely randomized design in a $2 \times 4$ factorial with two levels of L-glutamic acid (6.25\% and 12.5\%) combined with four levels of K vitamin (0.02; 0.2; 2.0 and $20.0 \mathrm{mg}$ of feed) each combination with four replicates of 10 animals. It was used Avian farm male broilers at 1 day of age, reared in electrically heated batteries with raised wire mesh floors and they were fed ad libitum with a basic diet containing essential L-amino acids, minerals and $\mathrm{K}$ vitamin. At the end of the experiment, the broilers were sacrificed through cervical dislocation and their femurs were removed, measured, fat removed and weighted. It was not observed a significant interaction among Lglutamic acid and $\mathrm{K}$ vitamin for the studied parameters. The non-collagenous protein levels were higher and the collagenous proteins levels were lower in the femurs of the animals fed with $6.25 \%$ of L-Glu. However, the total protein levels were not affected by the levels of L-glutamic acid and $\mathrm{K}$ vitamin. The levels of $\mathrm{K}$ vitamin had a decreasing quadratic effect on the levels of non-collagenous proteins and increasing effect on the level of collageonous proteins in the femurs. The composition on collagenous and non collagenous proteins can be used as a biochemical marker of leg abnormalities caused by low level of non-specific nitrogen.
}

Key Words: bone, collagenous proteins, glutamate, menadione, noncollagenous proteins 


\section{Introdução}

Problemas ósseos são uns dos principais fatores que limitam o desempenho de aves tipo carne. Frangos e perus de rápido crescimento, que ganham peso sobretudo em menor idade, são os que têm mais problemas de pernas e maiores perdas em comparação a aves de crescimento mais tardio (Day, 1990; Dibmer, 2007). Em vários trabalhos, os animais com alta incidência de problemas de pernas apresentaram significativamente, maiores teores de proteínas não-colagenosas ou extraíveis com ácido etilenodiamina tetracético (EDTA) (Guimarães et al., 1993; Ribeiro et al., 1995a, b; Rodrigues \& Moraes, 1995; Guimarães et al., 1996). Mudanças nas concentrações de proteínas não-colagenosas podem contribuir para a fragilidade do osso por interferirem na completa mineralização e/ou na arquitetura normal (Vetter et al., 1991; Young, 2003).

Entre as proteínas não-colagenosas, destacam-se aquelas que contêm resíduos do aminoácido $\gamma$-carboxiglutâmico (Gla), denominadas Gla-proteínas (osteocalcina e Gla-proteína da matriz). A função metabólica da vitamina K é como cofator para a carboxilase dependente de vitamina $\mathrm{K}$, uma enzima microssomal responsável pela conversão pós-síntese de resíduos específicos de glutamil a $\gamma$-carboxiglutamil (Gla) (Suttie, 1991; Saraiva \& Lazarewtti-Castro, 2002; Klack \& Carvalho, 2006). A exigência de vitamina Kem aves baseia-se nas respostas de coagulação sanguínea; não existe informação sobre a quantidade necessária de vitamina K para crescimento ósseo (Pearson Debra, 2007; Fleming et al., 1998). O objetivo neste trabalho foi verificar os efeitos dos níveis de ácido L-glutâmico e vitamina K da dieta sobre o conteúdo de proteínas não-colagenosas, proteínas colagenosas e proteínas totais de tibiotarsos e fêmures de pintos de corte aos 14 dias de idade.

\section{Material e Métodos}

O experimento foi montado em delineamento inteiramente casualizado, em esquema fatorial $2 \times 4$, composto de dois níveis de ácido L-glutâmico (6,25 e 12,5\%) combinados com quatro níveis de vitamina $\mathrm{K}(0,02 ; 0,20 ; 2,0$ e 20,0 mg/kg de dieta). Utilizaram-se 256 pintos machos de 1 dia, Avian Farm, de peso médio de 48 g, distribuídos aleatoriamente nos tratamentos, totalizando quatro repetições de oito animais por tratamento.

As dietas foram compostas a partir de uma dieta básica purificada (Tabela 1) contendo todos os aminoácidos essenciais, minerais e vitaminas, exceto vitamina $\mathrm{K}$, e suplementada com os dois níveis de ácido L-glutâmico
Tabela 1 - Composição da dieta purificada

\begin{tabular}{lr}
\hline Ingrediente & $\%$ \\
\hline Aminoácidos essenciais $^{1}$ & 9,77 \\
Mistura vitamínica $^{2}$ & 3,45 \\
Mistura mineral $^{3}$ & 9,98 \\
Óleo de soja $^{\text {Bicarbonato de sódio }}$ & 15,00 \\
Amido q.s.p. & 1,00 \\
\hline
\end{tabular}

${ }^{1}$ L-arginina, 1,20\%; L-histidina $\mathrm{HCl} \mathrm{H}_{2} \mathrm{O}, 0,42 \%$; L-lisina $\mathrm{HCl}, 1,14 \%$; L-tirosina, 0,57\%; L-fenilalanina, 0,63\%; L-triptofano, 0,18\%; DL-metionina, $0,41 \%$; L-cistina, 0,41\%; L-treonina, 0,76\%; L-leucina, 1,26\%; L-isoleucina, 0,76\%; L-valina, 0,88\%; L-prolina, 0,50\%; e glicina, 0,74\% (Baker \& Han, 1994).

2 Quantidade/kg de dieta: cloreto de colina 60\%, 3,3 g; retinil palmitato, $5.000 \mathrm{UI}$; colecalciferol, $22.500 \mathrm{UI}$; D-tocoferil acetato, $22 \mathrm{UI}$; inositol, $1 \mathrm{~g}$; riboflavina, $9 \mathrm{mg}$; tiamina $\mathrm{HCl}$, 6,0 mg; pantotenato de cálcio, $20 \mathrm{mg}$; niacina, $50 \mathrm{mg}$; piridoxina, $8 \mathrm{mg}$; ácido fólico, $2 \mathrm{mg}$; biotina, 0,3 mg; $\mathrm{B}_{12}$ (0,1\%), $20 \mathrm{mg}$; BHT, 0, $125 \mathrm{mg}$; excipiente, $30 \mathrm{~g}$; menadiona sódio bissulfito variável $(0,02 ; 0,2 ; 2,0$ e 20,0 mg/kg de dieta) (Featherston \& Rogler, 1978).

${ }^{3}$ Quantidade/kg de dieta: $\mathrm{CaCO}_{3}, 18,6526 \mathrm{~g} ; \mathrm{CaHPO}_{4} \cdot \mathrm{H} 2 \mathrm{O}, 30,53 \mathrm{~g} ; \mathrm{K}_{2} \mathrm{HPO}_{4}$, 11,2 g; NaCl, 6,0 g; $\mathrm{FeSO}_{4}$, 0,2 g; $\mathrm{ZnO}, 0,1225$ g; $\mathrm{CuSO}_{4} .5 \mathrm{H}_{2} \mathrm{O}, 0,015$ g; $\mathrm{MnSO}_{4} \cdot \mathrm{H}_{2} \mathrm{O}, 0,51 \mathrm{~g} ; \mathrm{KI}, 0,04 \mathrm{~g}, \mathrm{MgCO}_{3}, 2,5 \mathrm{~g} \mathrm{Na}_{2} \mathrm{MoO}_{4} \cdot 2 \mathrm{H}_{2} \mathrm{O}, 1,0 \mathrm{mg} ; \mathrm{Na}_{2} \mathrm{SeO}_{3}$, $0,22 \mathrm{mg}$ e excipiente (casca de arroz) 30,0 g (Featherston \& Rogler, 1978).

combinados com um dos quatro níveis de vitamina K. As aves foram alojadas em baterias aquecidas com piso de tela elevado e receberam água e ração à vontade durante todo o período experimental de 14 dias. Ao término do período experimental, cinco aves de cada tratamento foram sacrificadas por deslocamento cervical e os fêmures de ambas as pernas, movidos.

Todo o tecido aderente foi retirado e posteriormente os ossos foram medidos, pesados, desengordurados com éter de petróleo por 10 horas, secos e novamente pesados. Posteriormente, cinco ossos de cada grupo foram submetidos à extração das proteínas não-colagenosas com EDTA (ácido etilenodiamina tetracético) (Hauschka \& Gallop, 1977). O fim da extração foi determinado com o ácido oxálico, que permite identificar a desmineralização completa. Os teores de proteínas não-colagenosas foram determinados de acordo com Bradford (1976), utilizando-se albumina sérica bovina como padrão. Os ossos, após a desmineralização, foram lavados exaustivamente com água destilada e deionizada para eliminação do EDTA e usados para estimar o teor de proteínas colagenosas, obtido multiplicando-se o teor de nitrogênio pelo fator 6,25 e os teores de proteínas totais, pela soma dos teores de proteínas não-colagenosas e de proteínas colagenosas.

Os dados foram submetidos à análise de variância pelo Sistema de Análises Estatísticas e Genéticas - SAEG (UFV, 2000). Os efeitos dos níveis de ácido L-glutâmico foram testados pelo teste $\mathrm{F}$ e os efeitos dos níveis de vitamina $\mathrm{K}$, quando necessário, por regressão. A escolha do melhor modelo baseou-se no coeficiente de determinação $\left(R^{2}\right)$, na significância dos coeficientes de regressão pelo teste t e na coerência com o fenômeno biológico. 


\section{Resultados e Discussão}

Não houve interação significativa ácido L-glutâmico $\times$ vitamina $\mathrm{K}$ para os teores de proteínas colagenosas, proteínas não-colagenosas e proteínas totais, tanto para fêmur como para tibiotarsus nos frangos aos 14 dias de idade (Tabela 1). Isoladamente, os níveis de vitamina $\mathrm{K}$ tiveram efeito quadrático $(\mathrm{P}<0,01)$ dos níveis de vitamina K sobre os teores de proteínas não-colagenosas e proteínas colagenosas, tanto do fêmur como do tibiotarsus. Os teores de proteínas totais não foram influenciados ( $\mathrm{P}>0,01)$ pelos níveis de vitamina K e ácido L-glutâmico das dietas.

A vitamina K é, reconhecidamente, essencial para a $\gamma$-carboxilação de resíduos glutamil (GLU) a $\gamma$-carboxiglutâmico (GLA) de proteínas ósseas (Olson, 1984). A ausência, ou mesmo a deficiência de vitamina $\mathrm{K}$, reduz a $\gamma$-carboxilação e, consequentemente, as proteínas sem os resíduos GLA teriam sua função alterada, podendo comprometer a integridade do tecido ósseo (Vermmer et al., 1995).

Resultados de muitas pesquisas sugerem que a vitamina K pode estar envolvida na manutenção da saúde do tecido esquelético, possivelmente envolvida no controle da remodelagem óssea. Entretanto, existe o paradoxo do desenvolvimento do tecido ósseo, aparentemente normal na deficiência de vitamina K (Binkley \& Suttie, 1995). Rodrigues et al. (1996) estudaram anomalias ósseas em pintos de corte alimentados com dietas purificadas suplementadas com ácido L-glutâmico e vitamina K e não observaram efeito dos níveis de vitamina K nos teores de proteínas colagenosas e não-colagenosas.

Os teores de proteínas não-colagenosas dos ossos foram maiores nas aves alimentadas com dietas suplementadas com 6,25\% de L-glutâmico em comparação àquelas alimentadas com dietas com 12,5\% de L-glutâmico, cujos valores de proteínas não-colagenosas foram de 3,23 mg\% (Figura 1). Os valores mais baixos foram observados nas aves com melhor desempenho e menor incidência de problemas de pernas (Rodrigues, 2001), similar ao observado por Ribeiro et al. (1995b), Guimarães et al. (1996) e Silva et al. (2000), o que confirma que as anormalidades do tecido ósseo podem estar associadas aos altos teores de proteínas não-colagenosas dos ossos das pernas de frangos de corte. Para os teores de proteínas colagenosas, verificou-se uma inversão, pois os maiores valores foram observados com o fornecimento da dieta com $12,5 \%$ de ácido L-glutâmico.

Ribeiro et al. (1995b) verificaram que aves alimentadas com dieta contendo 12,5\% de L-glutâmico apresentaram maior teor de proteínas colagenosas (29,63 mg\%) em comparação àquelas alimentadas com dietas com 6,25\% de L-glutâmico e 26, 39 mg\% de proteínas não-colagenosas. Rodrigues et al. (1996) observaram aumento dos teores de proteínas colagenosas de pintos alimentados com dietas suplementadas com $12,5 \%$ de L-glutâmico em relação àqueles alimentados com 5\% de L-glutâmico. Entretanto, Silva et al. (2000) forneceram uma dieta purificada

Tabela 1 - Teores médios de proteínas colagenosas, proteínas não-colagenosas e proteínas totais no fêmur de frangos de corte aos 14 dias de idade

\begin{tabular}{|c|c|c|c|c|}
\hline \multirow[b]{2}{*}{ Característica } & \multicolumn{4}{|c|}{ Ácido L-glutâmico (\%) } \\
\hline & Vitamina K (mg/kg de dieta) & 6,25 & 12,5 & Médias \\
\hline \multirow[t]{5}{*}{ Proteínas colagenosas (mg \%) } & 0,02 & 25,21 & 26,20 & $* *$ \\
\hline & 0,2 & 26,33 & 27,13 & 25,71 \\
\hline & 2,0 & 27,27 & 28,05 & 26,73 \\
\hline & 20,0 & 27,49 & 28,26 & 27,66 \\
\hline & & & & 27,88 \\
\hline Médias* & & $26,58 b$ & $27,41 \mathrm{a}$ & \\
\hline \multirow[t]{5}{*}{ Proteínas não-colagenosas (mg \%) } & & & & $* *$ \\
\hline & 0,02 & 5,29 & 4,47 & 4,88 \\
\hline & 0,2 & 4,32 & 3,48 & 3,90 \\
\hline & 2,0 & 3,34 & 2,59 & 2,97 \\
\hline & 20,0 & 3,13 & 2,38 & 2,76 \\
\hline Médias* & & $4,02 \mathrm{a}$ & $3,23 b$ & \\
\hline \multirow[t]{4}{*}{ Proteína total (mg \%) } & 0,02 & 30,50 & 30,67 & 30,59 \\
\hline & 0,2 & 30,65 & 30,61 & 30,63 \\
\hline & 2,0 & 30,61 & 30,64 & 30,63 \\
\hline & 20,0 & 30,62 & 30,63 & 30,63 \\
\hline Médias* & & $30,60 a$ & $30,65 a$ & \\
\hline
\end{tabular}

* Médias seguidas por letras diferentes diferem entre si pelo teste $\mathrm{F}$.

** Efeito quadrático $(\mathrm{P}<0,01)$. 
suplementada com L-glutâmico (5, 10 e 15\%) e vitamina $\mathrm{D}_{3}$ $(0,5.000,10.000$ e $15.000 \mathrm{UI} / \mathrm{kg}$ de dieta) para pintos de corte e não observaram efeito nos teores de proteínas colagenosas. O aumento do nível de 6,25\% de L-glutâmico para $12,5 \%$ aumentou a fração colagenosa e diminuiu a nãocolagenosa, o que pode explicar a redução da incidência de anormalidades do tecido ósseo em pintos de corte alimentados com dietas com 12,5\% de ácido L-glutâmico. Essa relação entre os teores de proteínas não-colagenosas e a incidência de problemas de pernas pode ser explicada pelo aumento de Gla-proteínas (componentes das proteínas não-colagenosas), que não somente inibe a mineralização óssea, como também pode estimular a liberação de cálcio do osso (Price, 1985; Vermeeer et al., 1995).

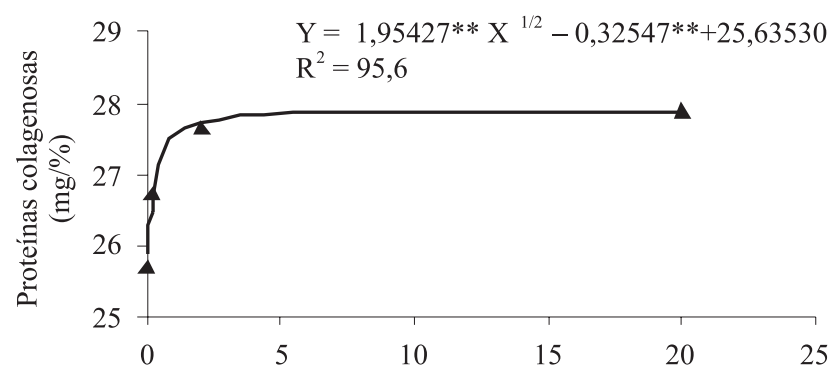

Níveis de vitamina $\mathrm{K}$ (mg/kg ração)

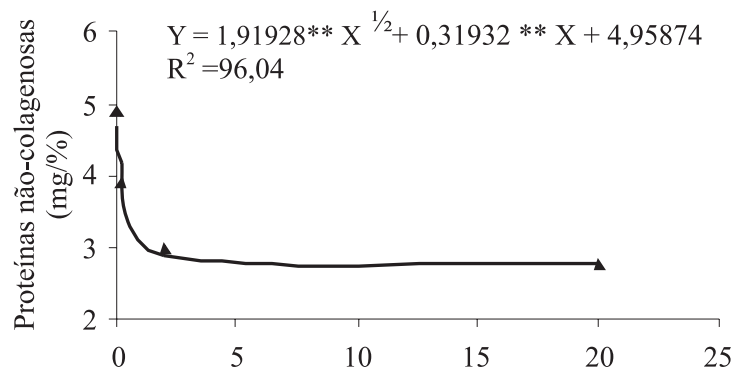

Níveis de vitamina K (mg/kg ração)

Figura 1 - Estimativa do teor de proteínas colagenosas e não-colagenosas no fêmur de frangos de corte alimentados com rações suplementadas com vitamina K e ácido L-glutâmico.

\section{Conclusões}

A vitamina K pode estar envolvida na manutenção da saúde do tecido esquelético, possivelmente por estar envolvida no controle da remodelagem óssea. Entretanto, na deficiência de vitamina K, pode ocorrer desenvolvimento aparentemente normal do tecido ósseo. A elevação do nível de 6,25\% de ácido L-glutâmico para 12,5\% aumenta a fração colagenosa e diminui a fração de proteínas ósseas nãocolagenosas e isso pode explicar a redução da incidência de anormalidades do tecido ósseo em pintos de corte alimentados com dietas com 12,5\% de ácido L-glutâmico.

\section{Referências}

BAKER, D.H.; HAN, Y. Ideal amino acid profile for chicks during the first three weeks posthatching. Poultry Science, v.73, n.9, p.1441-47, 1994.

BINKLEY, N.C.; SUTTIE, J.W. Vitamin K and osteoporosis. Journal of Nutrition, v.125, n.7, p.1812-1821, 1995.

BRADFORD, M. A rapid and sensitive method for the quantification of microgam quantities of protein utilizing the principle of protein dye binbing. Analytical Biochemistry, v.72, n.7, p.248-54, 1976.

DAY, E.J. Future research needs focus on new, old problems. Feedstuffs, v.23, n.62, p.12-15, 1990.

DIBNER, J.J.; RICHARDS, J.D.; KITCHELL, M.L. et al. Metabolic challenges and early bone development. Journal Applied Poultry Research, v.16, n.1, p.126-137, 2007.

FEATHERSTON, W.E.; ROGLER, J.C. Methionine-cystine interrelationship in chiks fed diets containing suboptimal levels of methionine. Journal of Nutrition, v.108, n.10, p.195458, 1978.

FLEMING, R.H.; McCORMACK, H.A.; WHITEHEAD, C.C. Bone structure and strength at different ages in laying hens and effects of dietary particulate limestone, vitamin $\mathrm{K}$ and ascorbic acid. British Poultry Science, v.39, n.3, p.434-440, 1998.

GUIMARÃES, V.M.; MORAES, G.H.K.; FONSECA, J.B. et al. Efeitos do aminoácido L-glutâmico, L-prolina e L-lisina da dieta no desenvolvimento e incidência de problemas de pernas em pintos de corte. Revista Brasileira de Zootecnia, v.22, n.4, p.584-90, 1993.

GUIMARÃES, V.M.; MORAES, G.H.K.; FONSECA, J.B. et al. Efeitos de aminoácidos não essenciais da dieta sobre glutamatooxaloacetato transaminase hepática e composição química parcial de tíbias e fêmures de pinto de corte. Revista Brasileira de Zootecnia, v.25, n.3, p.481-493, 1996.

HAUSCHKA, P.V.; GALLOP, P.M. Purification and calcium binding properties of osteocalcin, the gamma-carboxyglutamic acidcontaning proteins of bone. In: WEISSIERMAN, R.H. (Ed.). Calcium binding proteins and calcium function. Amsterdan: Elsevier, 1977. p.338-347.

KLACK, K.; CARVALHO, J.F. Vitamina K: metabolismo, fontes e interação com o anticoagulante Varfarina. Revista Brasileira de Reumatologia, v.46, n.6, p.398-406, 2006.

OLSON, R.E. The function and metabolism of vitamin K. Annual Review of Nutrition, v.4, p.281-337, 1984.

PEARSON DEBRA, A. Bone health and osteoporosis: the role of vitamin $\mathrm{K}$ and potential antagonismbyanticoagulants. Nutrition in Clinical Practice, v.22, n.5, p.517-544, 2007.

PRICE, P.A. Vitamin K-dependent formation of bone Gla-protein (osteocalcin) and its function. In: AUBARCH, G.D. (Ed). Vitamins and hormones. New York: Academic Press, 1985. v.42, p.65-109.

PRICE, P.A.; WILLIAMSON, M.K. Effects of warfarin on bone. Journal Biological Chemistry, v.256, n.24, p.12754-59, 1981. 
RIBEIRO, M.; MORAES, G.H.K.; FONSECA, J.B. Efeitos de fontes e níveis de nitrogênio não específico em dietas purificadas no desempenho de pintos de corte. Revista Brasileira de Zootecnia, v.24, n.1, p.88-98, 1995a.

RIBEIRO, M.; MORAES, G.H.K.; FONSECA, J.B. Efeitos de ácido L-glutâmico, L-alanina e L-prolina da dieta em pintos de corte: I - Desempenho, incidência de problemas de pernas e composição química de fêmures. Revista Brasileira de Zootecnia, v.42, n.5, p.768-77, 1995b.

RODRIGUES, A.C.P. Níveis de ácido l-glutâmico e de vitamina $K$ no desempenho e deformidades ósseas e perfil de enzimas digestivas de pintos de corte alimentados com dietas purificadas. 2001. 130f. Tese (Doutorado em Zootecnia), Universidade Federal de Viçosa, Viçosa, MG.

RODRIGUES, A.C.P.; MORAES, G.H.K. Efeitos do ácido glutâmico e da vitamina $\mathrm{K}$ da dieta no desempenho e nas anomalias nas pernas de pintos de corte. Revista Ceres, v.42, n.241, p.270-78, 1995.

RODRIGUES, A.C.P.; MORAES, G.H.K.; ROSTAGNO, H.S. et al. Efeitos do ácido L-glutâmico e da vitamina K no comprimento e na composição química parcial de tíbias e fêmures de pintos de corte. Revista Ceres, v.43, n.249, p.567-80, 1996.

SARAIVA, G.L.; LAZARETTI-CASTRO, M. Marcadores bioquímicos da remodelação óssea na prática clínica. Arquivo Brasileiro de Endocrinologia e Metabolismo, v.46, p.72-78, 2002.

SILVA, F.A.; MORAES, G.H.K.; RODRIGUES, A.C.P. et al. Efeitos do ácido L-glutâmico e da vitamina D3 nos fêmures e tibiotarsos de pintos de corte. Revista Brasileira de Zootecnia, v.30, n.6, p.2078-2085, 2001.

SUTTIE, J.W. Vitamin K. In: MACHLIN, L.J. (Ed.) Handbook of vitamins 2.ed. New York: Marcel Dekker, 1991. p.145-194.

UNIVERSIDADE FEDERAL DE VIÇOSA - UFV. Sistema de Análises Estatísticas e Genéticas - SAEG. Viçosa, MG, 1999. (CD-ROM).

VERMEER, C.; JIE, K.S.G.; KNAPEN, M.H.J. Role of vitamin K in bone metabolism. Annual Review of Nutrition, v.15, p.1-22, 1995.

VETTER, V.; FISHER, L.W.; MINTZ, K.P. et al. Osteogenesis imperfecta: changes in noncollagenous protein in bone. Journal Bone Mineralization Research, v.6, n.5, p.501-505, 1991.

YOUNG, M.F. Bone matrix proteins: their function, regulation, and relationship to osteoporosis. Osteoporosis International, v.14, n.3, p.35-42, 2003. 